\title{
Identification and distribution of Brachyspira species in feces from finishing pigs in Argentina
}

\author{
Alicia Carranza1 (D), Julián Parada ${ }^{1,2}$ (D), Pablo Tamiozzo ${ }^{1}$ (D), Malena Flores León ${ }^{1}$, Pablo Camacho ${ }^{1}$ \\ Gabriel Di Cola ${ }^{1}$, Enrique Corona-Barrera ${ }^{3}$ (D), Arnaldo Ambrogi ${ }^{1}$ and Gustavo Zielinski ${ }^{4}$ (D)
}

1. Department of Animal Pathology, Faculty of Agronomy and Veterinary, National University of Rio Cuarto, Río Cuarto, Argentina; 2. National Scientific and Technical Research Council (CONICET), Córdoba, Argentina; 3. Faculty of Veterinary Medicine and Animal Science, Autonomous University of Tamaulipas, Victoria, México; 4. National Agricultural Technology Institute (INTA), Marcos Juárez, Córdoba, Argentina.

Corresponding author: Julián Parada, e-mail: jparada@ayv.unrc.edu.ar

Co-authors: AC: acarranza@ayv.unrc.edu.ar, PT: ptamiozzo@ayv.unrc.edu.ar, MFL: malefloresleon@hotmail.com, PC: pablocamacho1@hotmail.com, GDC: gdicola@ayv.unrc.edu.ar, EC: enriquecoronas@gmail.com, AA: naly@ayv.unrc.edu.ar, GZ: zielinski.gustavo@inta.gov.ar

Received: 03-09-2020, Accepted: 22-01-2021, Published online: 10-03-2021

doi: www.doi.org/10.14202/vetworld.2021.607-613 How to cite this article: Carranza A, Parada J, Tamiozzo P, Flores León M, Camacho P, Di Cola G, Corona-Barrera E, Ambrogi A, Zielinski G (2021) Identification and distribution of Brachyspira species in feces from finishing pigs in Argentina, Veterinary World, 14(3): 607-613.

\begin{abstract}
Background and Aim: Brachyspira are Gram-negative, aerotolerant spirochetes that colonize the large intestine of various species of domestic animals and humans. The aim of this study was to determine the presence and distribution of different species of Brachyspira presents in feces from finishing pigs in Argentina.

Materials and Methods: Fecal samples ( $\mathrm{n}=1550)$ were collected from finishing pigs in 53 farms of the most important swine production areas of Argentina, and Brachyspiras species were identified by bacteriological and molecular methods.

Results: The regional prevalence of Brachyspira spp. was at the level of 75.5\% (confidence interval 95\%, 62.9-87.9), and it was lower among those farms with $>1001$ sows. One hundred and twenty-eight isolates of Brachyspira were properly identified and the species found were: Brachyspira hyodysenteriae, Brachyspira pilosicoli, Brachyspira innocens, and Brachyspira murdochii. B. hyodysenteriae and B. pilosicoli had low prevalence (1.9\% and $7.5 \%$, respectively), B. innocens was isolated from $34 \%$ of the farms and B. murdochii was found in $39.6 \%$.
\end{abstract}

Conclusion: The present study provides epidemiological data about herd prevalence of the different Brachyspira species in Argentina, showing that the prevalence figure seems to be higher than that reported in other countries.

Keywords: Brachyspira species, diagnosis, herd prevalence, intestinal spirochetes, swine.

\section{Introduction}

Brachyspira are Gram-negative, aerotolerant spirochetes that colonize the large intestine of various species of domestic animals and humans. Brachyspira hyodysenteriae has been recognized as the etiological agent of swine dysentery, a swine disease characterized by a severe muco-hemorrhagic colitis in growing pigs, and Brachyspira pilosicoli is responsible for a condition known as porcine colonic spirochetosis, which has a negative impact on pig production as a consequence of the muco-catarrhal colitis, green or brown diarrhea, and the poor performance of fattening pigs [1]. Other known species of the genus Brachyspira are, Brachyspira innocens, Brachyspira murdochii, and Brachyspira intermedia which are also found in pigs colon; these species are also responsible for mild colitis in pigs except $B$. innocens that is regarded as non-pathogenic. However, the previous reports on

Copyright: Carranza, et al. Open Access. This article is distributed under the terms of the Creative Commons Attribution 4.0 International License (http://creativecommons.org/licenses/ by/4.0/), which permits unrestricted use, distribution, and reproduction in any medium, provided you give appropriate credit to the original author(s) and the source, provide a link to the Creative Commons license, and indicate if changes were made. The Creative Commons Public Domain Dedication waiver (http:// creativecommons.org/publicdomain/zero/1.0/) applies to the data made available in this article, unless otherwise stated. clinical cases and experimental studies [2,3] have found that one single species of Brachyspira or mixed infection, that is, various species of Brachyspira in a host could cause mild degrees of colitis. Other reports showed B. innocens, B. murdochii, and B. intermedia individually associated with pathological colitis [4], or in mixed infections with other infectious agents [5]. Recently, Brachyspira hampsonii has been recognized as a new species of Brachyspira that is pathogenic as it has been isolated from clinical cases of swine dysentery in Canada [6].

Isolation and identification of Brachyspira spp. by bacteriology are not a straightforward approach, because of their slow growth and the difficulty of getting isolates in pure culture. At present, different molecular methods are available for detection and identification of Brachyspira species from fecal samples $[7,8]$, or from bacteriological cultures [9], but the protocols need to be updated continuously [10]. One of the most useful genes to assess the diagnosis of Brachyspira spp. is the NADH oxidase (nox), a relatively conserved gene amongst Brachyspira spp., which allows differentiation and proper identification of the different species [9]. In Latin America, limited studies were carried out concerning the presence of different species of Brachyspira. In Brazil, some 
regional studies identified $B$. hyodysenteriae and $B$. pilosicoli in pigs $[11,12]$. In Mexico, strongly and weakly hemolytic spirochetes were identified in $22 \%$ of pig farms [13]. In Argentina, although both pathogenic and non-pathogenic Brachyspira spp. have been identified by different diagnostic methods, very few epidemiological studies have been conducted, and thus little is known about the presence and distribution of the different Brachyspira species [14].

The aim of this study was to determine the presence and distribution of different species of Brachyspira present in feces from finishing pigs in Argentina.

\section{Materials and Methods \\ Ethical approval}

The study was approved by "Comité de Ética de la Investigación" (RR 852/11) of the National University of Río Cuarto (UNRC). All animal procedures carried out in our study were performed in accordance with international regulations.

\section{Study period and location}

In order to determine the prevalence of infection in the Pampean region of Argentina, the main pig producing area in the country, 53 commercial farrow-to-finish pig farms were sampled between October 2011 and March 2013.

\section{Farms, animals, and samples}

According to the 2012 Integrated System for Animal Health Management, provided by the National Animal Health, Food Safety and Quality Service of Argentina, at the moment of the present study, the number of confinement pig farms with more than 200 sows in the region was 322 , with a total figure of 153,350 sows. Most farms (84\%, 270 farms) were located in the provinces of Buenos Aires (37\%), Cordoba (24\%), Santa Fe (16\%), and Entre Ríos (7\%). The number of farms necessary to assess the prevalence of Brachyspira spp. positive farms in the region was calculated according to Thrusfield [15], considering an expected prevalence of $50 \%$, with $95 \%$ of confidence, and a precision of $13 \%$. Then, a stratified sampling method was designed according to the number of farms in each province.

The number of fecal samples to be collected was $\mathrm{n}=30$ as to detect the presence of at least one positive sample for intestinal spirochaetes [15]. Samples were collected from pigs of 22 weeks of age, with or without diarrhea and taken directly from the rectum of pigs by manual stimulation, placed in polyethylene bags and put at $4{ }^{\circ} \mathrm{C}$ until reaching the laboratory for processing, which was achieved no longer than $48 \mathrm{~h}$ after collection. A total of 1550 fecal samples were collected.

Afarm was considered positive when Brachyspira spp. growth characteristic on selective culture plates was confirmed by the observation of Gram-negative stained spirochaetes under optical microscopy.

\section{Bacteriology and biochemical identification}

The feces sample were plated onto Brachyspira selective medium (BSM) made up of Columbia Agar (Oxoid Ltd., Hants, UK) supplemented with 7.0\% horse blood and the antibiotics colistin $(25 \mathrm{mg} / \mathrm{mL})$, vancomycin $(25 \mathrm{mg} / \mathrm{mL})$, and spectinomycin $(400 \mathrm{mg} / \mathrm{mL})$ (Rosco Diagnostica, Taastrup, Denmark). Inoculated plates were incubated at $42^{\circ} \mathrm{C}$ for 7 days in anaerobic jars, using AnaeroGen GasPak system (Oxoid Ltd., Hants, UK). After the incubation, smears were made from positive culture plates that showed the growing characteristic of Brachyspira (strongly or weakly hemolytic). Brachyspira isolation was confirmed by observation of negative Gram-stained spirochetes using light microscopy examinations. Prime isolates were subcultured on BSM to obtain pure cultures. Brachyspira isolates were identified by biochemical testing (Rosco Diagnostica, Taastrup, Denmark) for the preliminary identification of species according to a method previously described [16]. Pure isolates were at $-70^{\circ} \mathrm{C}$ for further purposes.

\section{Identification by polymerase chain reaction (PCR)}

DNA from isolates was extracted using an organic extraction method (DNAzol, Invitrogen, USA). Two PCR approaches were used for species-specific identification of the Brachyspira isolates: (i) Duplex PCR for the identification of $B$. pilosicoli and B. hyodysenteriae [7] and (ii) for any other Brachyspira species restriction fragment length polymorphism-PCR (RFLP-PCR) [9,17], with some modifications. For the RFLP-PCR, the products were digested with $D p n$ II and Scf I and the fragments were separated on a $3 \%$ agarose gel by electrophoresis and stained with ethidium bromide. The standardization of the PCR testing was done using DNA from reference strains of B. hyodysenteriae, B. pilosicoli, B. murdochii y, and $B$. innocens provided by Dr. Enrique Corona-Barrera (Mexico).

\section{Identification by sequencing}

Sequencing was carried out particularly on isolates for which biochemical identification was not clear, so the species identification was done by nox gene PCR amplification followed by sequencing using primers as described previously [18]. Briefly, the PCR products were purified by the commercial kit Puriprep S (Inbio Highway, Tandil, Argentina), quantified (NanoDrop, ND 1000, Thermo Fisher Scientific, USA), and sequenced (ABI PRISM ${ }^{\circledR}$ 3130xl Genetic Analyzer, Applied Biosystem, CA, USA). The sequences were edited using BioEdit, aligned with ClustalW and compared with GenBank database using BLAST.

\section{Statistical analysis}

Brachyspira prevalence was calculated by dividing the number of positive farms by the total number of sampled farms in a region or province. The prevalence of a particular Brachyspira species was calculated by dividing the number of positive farms for 
that particular species by the total number of sampled farms. Statistical analysis, including interquartile range (IQR), Pearson's Chi-squared test, confidence interval (CI), and standard deviation (SD), was carried out using Epidat software version 3.1 (Xunta de Galicia, OPS-WHO, Spain).

\section{Results}

The number of herds necessary to estimate the prevalence was $n=49$. In addition, four farms of 150 sows located in the area of the study were also included as they sent samples to the diagnostic laboratory at university, giving them a total of 53 farms in the study. Farms with more than 200 sows represented $15.2 \%$ of the total of farms, for which a figure of 40,585 sows was recorded. The mean of herd size in this study was 500 sows (IQR=300-1000).

The regional prevalence of herds infected with different Brachyspira species was 75.5\% (CI 95\%, 62.9-87.9); in other words, 40 of the 53 sampled farms were culture positive for Brachyspira. The highest occurrence of Brachyspira spp. was observed in the province of Córdoba. Many species of intestinal spirochetes were found in that region (Table-1). In the provinces of Buenos Aires, Córdoba and Santa $\mathrm{Fe}$ only B. pilosicoli was found, and in Córdoba Province, B. hyodysenteriae was also detected (Table-2).

Farms were categorized in quartiles (C1-C4) according to the number of sows, and the proportion of positive herds for each quartile was calculated (Table-3). No statistical difference between herd size and presence of Brachyspira was found. The prevalence of Brachyspira spp. was lower (37\%) into the upper quartile (C4), among the larger farms (>1001 sows) (Chi-square Pearson=7.36, $\mathrm{p}=0.0613$ ).

Characteristic growth of intestinal spirochetes on cultured plates was confirmed by Gramstained smears, followed by microscopy. Isolation of Brachyspira on bacteriological culture was achieved on $19 \%(290 / 1550)$ of the cultured samples. The mean of Brachyspira positive cultures per farm was $18.9 \%$ $(\mathrm{SD}=17.3$, range 0-62.1), and the highest figure of positive culture was $50-62 \%$ observed in four farms with a herd size between 680 and 1200 sows.

One hundred and 28 Brachyspira isolates were properly identified by the different testing procedures; the Brachyspira species found in this study were $B$. hyodysenteriae, B. pilosicoli, B. innocens, and $B$. murdochii (Table-2). Although samples $(\mathrm{n}=30)$ from eight farms were recorded as Brachyspira culture positive, these isolates were not possible to identify by the molecular techniques. It was also observed that more than one species of Brachyspira was found in $22.5 \%(9 / 40)$ of the farms.

B. pilosicoli was isolated from farms of Buenos Aires $(\mathrm{n}=1)$, Córdoba $(\mathrm{n}=2)$, and Santa Fe $(\mathrm{n}=1)$. In some farms, B. pilosicoli was found alone in $16.7 \%$ $(5 / 30)$ of the samples, whereas in other farms, this

Table-1: Distribution of farms, samples taken, and prevalence of herds positive to Brachyspira spp. by province, positive samples for each diagnostic test, and frequency of Brachyspira spp. shedding pigs within-herd.

\begin{tabular}{|c|c|c|c|c|c|c|c|c|c|}
\hline \multirow[t]{2}{*}{ Province } & \multicolumn{2}{|c|}{ Samples } & \multicolumn{5}{|c|}{ Positive sample/test } & \multirow{2}{*}{$\begin{array}{c}\text { Provincial } \\
\text { prevalence } \\
(\%)\end{array}$} & \multirow{2}{*}{$\begin{array}{c}\text { Within-herd } \\
\text { frequency } \\
(\%)\end{array}$} \\
\hline & Farms & $\begin{array}{c}\text { Fecal } \\
\text { samples }\end{array}$ & $\begin{array}{c}\text { Biochemical } \\
\text { test }\end{array}$ & PCR & Sequencing & $\begin{array}{l}\text { Brachyspira } \\
\text { nontypeable }\end{array}$ & $\begin{array}{c}\text { Positive } \\
\text { farm }\end{array}$ & & \\
\hline $\begin{array}{l}\text { Buenos } \\
\text { Aires }\end{array}$ & 17 & 504 & 3 & 9 & 29 & 63 & 10 & 58.8 & 19.0 \\
\hline Córdoba & 22 & 637 & 29 & 5 & 28 & 68 & 20 & 91 & 21.8 \\
\hline Santa Fé & 8 & 229 & 2 & 4 & 12 & 20 & 5 & 62.5 & 16.1 \\
\hline Entre Ríos & 2 & 60 & - & - & - & 10 & 2 & 100 & 16.6 \\
\hline Other & 4 & 120 & 2 & 4 & 1 & 5 & 3 & 75 & 10 \\
\hline Total & 53 & 1550 & 36 & 22 & 70 & 166 & 40 & 75.5 & $\begin{array}{c}18.9 \\
\text { (Average) }\end{array}$ \\
\hline
\end{tabular}

$\mathrm{PCR}=$ Polymerase chain reaction

Table-2: Number of isolates of each identified Brachyspira species, number of positive farms, number of farms with only one or more than one Brachyspira species and regional prevalence of each identified Brachyspira species and distribution of the number of farms infected with each species in the different provinces.

\begin{tabular}{|c|c|c|c|c|c|c|c|c|c|}
\hline \multirow{2}{*}{$\begin{array}{l}\text { Brachyspira } \\
\text { species }\end{array}$} & \multirow[t]{2}{*}{ Isolates } & \multirow{2}{*}{$\begin{array}{l}\text { Positive } \\
\text { farms }\end{array}$} & \multirow{2}{*}{$\begin{array}{c}\text { Farms } \\
\text { with one } \\
\text { Brachyspira } \\
\text { species }\end{array}$} & \multirow{2}{*}{$\begin{array}{l}\text { Farms with } \\
\text { more than one } \\
\text { Brachyspira } \\
\text { species }\end{array}$} & \multirow{2}{*}{$\begin{array}{l}\text { Prevalence } \\
\text { of positive } \\
\text { farms (\%) }\end{array}$} & \multicolumn{4}{|c|}{ Geographical distribution } \\
\hline & & & & & & $\begin{array}{c}\text { Buenos } \\
\text { Aires }\end{array}$ & Córdoba & Santa Fé & Other \\
\hline $\begin{array}{l}\text { Brachyspira } \\
\text { hyodysenteriae }\end{array}$ & 5 & 1 & 0 & 1 & 1.9 & - & 1 & - & - \\
\hline $\begin{array}{l}\text { Brachyspira } \\
\text { pilosicoli }\end{array}$ & 7 & 4 & 1 & 3 & 7.5 & 1 & 2 & 1 & - \\
\hline $\begin{array}{l}\text { Brachyspira } \\
\text { innocens }\end{array}$ & 49 & 18 & 10 & 8 & 34.0 & 7 & 9 & 1 & 1 \\
\hline $\begin{array}{l}\text { Brachyspira } \\
\text { murdochii }\end{array}$ & 67 & 21 & 12 & 9 & 39.6 & 6 & 8 & 5 & 2 \\
\hline
\end{tabular}


Table-3: Categorization of farms in quartiles according to herd breeding size, number of Brachyspira spp. positive farms, and percentage of positive farms in each category.

\begin{tabular}{lccc}
\hline Category & $\mathbf{n}$ & Positives & \% farms + \\
\hline$<300$ sows (C1) & 18 & 15 & 81.30 \\
$301-500$ sows (C2) & 11 & 9 & 81.80 \\
$501-1000$ sows (C3) & 16 & 13 & 81.25 \\
$>1001$ sows (C4) & 8 & 3 & 37.50 \\
\hline
\end{tabular}

species was found together with $B$. innocens and B. murdochii in up to $23.3 \%$ and $46.6 \%$ of the samples, respectively.

Indole-negative $B$. hyodysenteriae was identified in one herd from Córdoba, in which $16.7 \%$ (5/30) of fecal samples were culture positive.

The most frequent Brachyspira species found were $B$. innocens and B. murdochii. B. innocens was found in $45 \%(24 / 53)$ of the farms and in ten farms, it was identified as the only Brachyspira species ranging from $3 \%$ to $30 \%$ of the positive samples, this species was also found in $8(12.2 \%)$ of the farms together with $B$. hyodysenteriae $(\mathrm{n}=1), B$. pilosicoli $(\mathrm{n}=2)$, and B. murdochii $(\mathrm{n}=8)$. The most frequent Brachyspira species found in this study was $B$. murdochii, as it was present in 53\% (28/53) of the Brachyspira culture positive farms. It was also recorded that some of the farms $(\mathrm{n}=4)$ had mixed Brachyspira infections, as found in four different farms where at least one sample of each farm had more than one Brachyspira species.

\section{Discussion}

This study was conducted on pig farms located in the most important swine production areas of Argentina, where there was no previous data recorded on the prevalence of Brachyspira. Four additional farms located in neighboring provinces with small number of sows were also included in the study.

Brachyspira was isolated from feces of pigs of all the provinces included in this study, which gave an isolation rate of $76 \%(40 / 53)$ of the samples taken from 53 farms with more than 200 sows. The prevalence of Brachyspira in pig farms has been reported in other countries. For instance, in 2000, it was found that $50 \%$ of the farms in Denmark were positive to isolation of intestinal spirochetes as Brachyspira was found in 79 pig farms; moreover, in that study, other porcine enteropathogens were also reported [19]. In Mexico, out of a total of 73 farms from pig production areas, $16(21.9 \%)$ were culture positive for intestinal spirochetes showing strong and weak hemolysis on blood agar plates [13]. However, the prevalence of Brachyspira positive farms in Argentina seems to be higher than that of Denmark and Mexico, whereas, in a study in Poland including finishing pigs from 20 farms, the prevalence of Brachyspira spp. was higher than $85 \%$ [20].

In other studies, intestinal spirochetes have been found in $63.2 \%(24 / 38)$ of pig farms in the state of Rio Grande do Sul (Brazil) and a remarkable prevalence of $100 \%$ was found in 22 farms with no use of antibiotics in the feed [11]. The relationship between the use of in-feed antibiotics and Brachyspira prevalence has been suggested previously [21,22]. Thereby, the use of antibiotics in the feed may be related to the high isolation rate found in our study, particularly in smaller farms ( $<300$ sows), where the use of antibiotics was less frequent (data not shown). The age of pigs at the time of sampling in this study may also influence the high prevalence found, as it has also been reported in a recent study [20].

Although no statistical association was found between herd size and isolation of Brachyspira spp., the prevalence of Brachyspira was lower in farms with $>1001$ sows $(\mathrm{C} 4)$. That could be due to more effective biosecurity measures and strategic programs on the use of antibiotics coupled with more technology applied to production.

In this study, a total of 290 samples were positive isolated and out of those, 128 isolates (44\%) were properly identified at the species level (Tables-1 and 2). In some studies, bacteriological culture has shown higher sensitivity for detecting $B$. hyodysenteriae and B. pilosicoli as compared to PCR [8] or other available diagnostic tests [23]. In our study, samples were considered positive when the characteristic hemolysis on culture plates was seem and confirmed by observing Gram-negative spirochetes on microscopic preparations. However, for some samples, it was not possible to identify them fully at species level. Brachyspira is regarded as a fastidious microorganism, which is a feature that reduces the success of identification of prime isolates as the growth sometimes is so poor that its replication ends up in no further growth on subcultured plates, so the amount of growth might not be sufficient in the first instance. In other cases, it was not possible to get pure culture after repeated subculturing.

Several studies have shown drawbacks on the identification of Brachyspira isolates. A study reported that out of 876 samples, only 67 intestinal spirochaetes isolates were obtained and just a few were identified but not so accurate due to variations on biochemical testing [13]. It has been pointed out that as there are known variations and discrepancies on the identification of Brachyspira species using biochemical tests, genotype identification is preferred and absolutely necessary for the proper identification of Brachyspira species [9]. Other studies have also reported issues on the identification of Brachyspira isolates by PCR, as there was trouble on $15 \%$ of the isolates in a study on Brachyspira from swine [4]. The issues on the identification of Brachyspira isolates could be due to genetic alterations on the bacterial genome, which may lead to no amplification of genetic material or no detection by the primers used in the PCR test. It is also known that more than one species of Brachyspira could be present in the same sample, so this might interfere with the punctual identification of the species by PCR techniques. 
The combination of bacteriological and molecular techniques has been used in several studies to address the difficulty of getting mixed results for the identification of samples at the species level [8], or to achieve proper detection of Brachyspira in mixed culture samples, or to identify a new species, such as Brachyspira suanatina which showed the same phenotype as $B$. hyodysenteriae [24]. Phenotypic variations are frequent in strains of $B$. hyodysenteriae; weakly hemolytic strains or negative indole strains may be present in a low percentage, as identified in the present study, which suggests that they must be confirmed by molecular techniques or sequencing [25-27]. But also, as Hampson et al. [28] have proposed, the diagnostic methodology needs to be reviewed regularly but should include both culture and molecular techniques. In our study, the combination of diagnostic testing allowed us the identification of more isolates at species level, which was more encouraging for our research.

The novel Brachyspira species, B. hampsonii and $B$. suanatina, were not identified by sequencing among the strong hemolytic isolates in our study. This is an important outcome as those species have been recognized as emergent species in clinical cases of swine dysentery $[6,24]$.

In our study, $B$. hyodysenteriae and B. pilosicoli were found in low prevalence $(1.9 \%$ and $7.5 \%$, respectively) at the Pampean region of Argentina, even lower than that described in other studies $(8.3 \%$ and $16.6 \%$, respectively) [14]. This may be related to the sampling strategy in the present study, where feces samples were taken from fattening pigs with and without diarrhea. In fact, isolation of $B$. hyodysenteriae from herds with clinical signs of swine dysentery was previously reported (data not shown). In other countries, B. hyodysenteriae was identified in $30.4 \%(24 / 79)$ of the isolates from pigs with diarrhea, while other Brachyspira species were isolated at a lower rate [4]. However, in a study from 600 samples of 20 farms with the previous infection history for $B$. hyodysenteriae, $24 \%$ of the samples were identified among this species, while $45 \%$ corresponded to $B$. innocens and a lower percentage for B. murdochii and B. pilosicoli, 13,5 , and $9.4 \%$, respectively [20].

The prevalence of $B$. pilosicoli in our study is similar to that reported in Brazil, where the isolation rate of B. pilosicoli was $4.36 \%$ in 46 farms in the area of Minas Gerais during a survey on intestinal pathogens [29]. The previous findings in the region reported a higher prevalence $(45.5 \%)$ from a total of 22 confined "wean to finish" and fattening farms that were on the no feed medication category [11]. A recent study in Poland also reported that the prevalence of herds infected with B. pilosicoli was $13.7 \%$ and with $B$. hyodysenteriae was $18.9 \%$ [30]. However, the differences in diagnostic strategies may also influence the results.

The most prevalent species detected in our study were $B$. innocens and $B$. murdochii. B. innocens was isolated from $34 \%$ of the sampled farms, being the only species recovered from $19 \%$ of the total farms. These results are similar to those found in Denmark [19], where these species were found in $34.2 \%$ and $19 \%$, respectively, also from herds with no clinical signs observed at the time of sampling. Another study also found those species as the most prevalent from animals with diarrhea [3], but other studies that collected sampled from pigs diarrhea found $B$. hyodysenteriae and $B$. pilosicoli as the most prevalent species [4].

As it has been mentioned above, the prevalence of $B$. murdochii was higher than that of $B$. innocens in this study; these results are consistent with previous studies where $B$. murdochii was the most prevalent among the weakly hemolytic Brachyspira species found in Austria [5].

Our findings show that more than one species of Brachyspira were found in nine farms, all the cases had in common the presence of $B$. innocens. In agreement with the previous studies $[4,8,9]$, different species were simultaneously identified in a farm, but mixed Brachyspira species were found in only four fecal samples. It was previously proposed [1], that more than one species of Brachyspira could be found in a sample, of which some might not be pathogenic, so this makes the diagnosis of pathogenic Brachyspira more difficult.

Several studies associate the presence of $B$. innocens and B. murdochii with mid catarrhal diarrhea and colitis in pigs with the presence of bugs in intestinal tissue samples [4]. Such enteric scenario has been reproduced experimentally [2]. In this context, the high prevalence of $B$. innocens and $B$. murdochii found in our study, as in other studies, emphasizes the need for further studies to determine the pathogenic potential of these spirochetes in healthy and diarrheic pigs, as it has been suggested previously [3].

To the best of our knowledge, this is the first study of herd prevalence and identification of the different Brachyspira species in the central region of Argentina, where most of the important pig production farms are located. The combination of different diagnostic tests allowed the identification of a larger number of isolates and this approach will help us to conduct further studies on pathogenicity, genotyping, and antibiotic susceptibility of Brachyspira species in Argentina.

\section{Conclusion}

The present study provides epidemiological data about herd prevalence of the different Brachyspira species in Argentina, showing that the prevalence figure seems to be higher than that reported in other countries.

\section{Authors' Contributions}

AC, JP, AA, and GZ designed the research work. AC, JP, MFL, and PC carried out the laboratory work. $\mathrm{AC}$ and PT analyzed the Bioinformatic data. AC and JP made the statistical analysis and drafted the 
manuscript. GDC, GZ, and EC helped in manuscript preparation. All authors have read and approved the final manuscript.

\section{Acknowledgments}

The authors acknowledge Dr. C. Vissio for her technical collaboration in the epidemiological analysis. This study was financially supported by resources from the Grupo Salud Porcina and Sec. CyT, PPI RR $\mathrm{N}^{\circ} 852 / 11$, National University of Río Cuarto, Argentina.

\section{Competing Interests} interests.

The authors declare that they have no competing

\section{Publisher's Note}

Veterinary World remains neutral with regard to jurisdictional claims in published institutional affiliation.

\section{References}

1. Hampson, D.J. and Burrough, E.R. (2019) Swine dysentery and Brachyspiral colitis. In: Zimmerman, J.J., Karriker, L.A., Ramirez, A., Schwartz, K.J., Stevenson, G.W. and Zhang, J., editors. Diseases of Swine. $11^{\text {th }}$ ed. Wiley-Blackwell, Hoboken, Iowa, USA. p951-70.

2. Jensen, T.K., Christensen, A.S. and Boye, M. (2010) Brachyspira murdochii colitis in pigs. Vet. Pathol., 47(2): 334-338.

3. Osorio, J., Carvajal, A., Naharro, G., Rubio, P., La, T., Phillips, N.D. and Hampson D.J. (2013) Identification of weakly haemolytic Brachyspira isolates recovered from pigs with diarrhoea in Spain and Portugal and comparison with results from other countries. Res. Vet. Sci., 95(3): 861-869.

4. Clothier, K.A., Kinyon, J.M., Frana, T.S., Naberhaus, N., Bower, L., Strait, E.L. and Schwartz, K. (2011) Species characterization and minimum inhibitory concentration patterns of Brachyspira species isolates from swine with clinical disease. J. Vet. Diagn. Invest., 23(6): 1140-1145.

5. Komarek, V., Maderner, A., Spergser, J. and Weissenböck, H. (2009) Infections with weakly haemolytic Brachyspira species in pigs with miscellaneous chronic diseases. Vet. Microbiol., 134(3-4): 311-317.

6. Mirajkar, N.S., Phillips, N.D., La, T., Hampson, D.J. and Gebhart, C.J. (2016) Characterization and recognition of Brachyspira hampsonii sp. nov., a novel intestinal spirochete that is pathogenic to pigs. J. Clin. Microbiol., 54(12): 2942-2949.

7. La, T., Phillips, N. and Hampson, D. (2003) Development of a Duplex PCR assay for detection of Brachyspira hyodysenteriae and Brachyspira pilosicoli in pig faeces. J. Clin. Microbiol., 41(7): 3372-3375.

8. Råsbäk, T., Fellström, C., Gunnarsson, A. and Aspán, A. (2006) Comparison of culture and biochemical tests with PCR for detection of Brachyspira hyodysenterie and Brachyspira pilosicoli. J. Microbiol. Methods, 66(2): 347-353.

9. Rohde, J., Rothkamp, A. and Gerlach, G.F. (2002) Differentiation of porcine Brachyspira species by a novel nox PCR-based restriction fragment length polymorphism analysis. J. Clin. Microbiol., 40(7): 2598-2600.

10. Aller Morán, L.M., Martínez-Lobo, F.J., Rubio, P. and Carvajal, A. (2016) Cross-reactions in specific Brachyspira spp. PCR assays caused by "Brachyspira hampsonii" isolates: Implications for detection. J. Vet. Diagn. Invest., 28(6): 755-759.
11. Barcellos, D., Razia, L. and Borowski, S. (2003) Occurrence and identification of swine intestinal spirochetes in industrial pig herds from two raising areas in the state of Rio Grande do Sul, Brazil, in relation to feed medication. Ciênc. Rural, 33(4): 725-729.

12. Daniel, A.G.S., Sato, J.P.H., Gabardo, M.P., Resende, T.P., Barcellos, D.E.S., Pereira, C.E.R., Vannucci, F.A. and Guedes, R.M.C. (2017) Minimum inhibitory concentration of Brazilian Brachyspira hyodysenteriae strains. Pesqui. Vet. Bras., 37(4): 331-338.

13. Corona-Barrera, E., Munguía, J., Rivera, K., Jiménez, F., Fajardo, R., Pradal-Roa, P. and Thomson, J. (2009) Isolation and identification of intestinal spirochaetes from pigs farms from the northern, central and southern areas of México. Vol. 5. In: $5^{\text {th }}$ International Conference on Colonic Spirochaetal Infections in Animals and Humans, León, España. p19-20.

14. Illanes, N., Pereyra, N., Carranza, A., Pelliza, B., Ambrogi, R., Tamiozzo, P. and Ambrogi, A. (2008) Presence of Brachyspira pilosicoli and Brachyspira hyodysenteriae in Argentina. $20^{\text {th }}$ International Pigs Veterinary Society Congress, Durban, South Africa. p244.

15. Thrusfield, M. (2007) Veterinary Epidemiology. $3^{\text {th }}$ ed. Wiley, New York, USA.

16. Hommez, J., Castryck, F., Haesebrouck, F. and Devriese, L. (1998) Identification of porcine Serpulina strains in routine diagnostic bacteriology. Vet. Microbiol., 62(2): 163-169.

17. Rohde, J. and Habighorst-Blome, K. (2012) An update on the differentiation of Brachyspira species from pigs with nox-PCR-based restriction fragment length polymorphism. Vet. Microbiol., 158(1-2): 211-215.

18. Chander, Y., Primus, A., Olivera, S. and Gebhart, C.J. (2012) Phenotypic and molecular characterization of a novel strongly hemolytic Brachyspira species, provisionally designated "Brachyspira hampsonii". J. Vet. Diagn. Invest., 24(5): 903-910.

19. Stege, H., Jensen, T.K., Møller, K., Bækbo, P. and Jorsal, S.E. (2000) Prevalence of intestinal pathogens in Danish finishing pig herds. Prev. Vet. Med., 46(4): 279-292.

20. Zeeh, F., de Luca, S., Nicholson, P., Grützner, N., Nathues, C., Perreten, V. and Nathues, H. (2018) Brachyspira hyodysenteriae detection in the large intestine of slaughtered pigs. $J$. Vet. Diagn. Invest., 30(1): 56-63.

21. Biksi, I., Lőrincz, M., Molnár, B., Kecskés, T., Takács, N., Mirt, D., Cizek, A., Pejsak, Z., Martineau, G.P., Sevin, J.L. and Szenci, O. (2007) Prevalence of selected enteropathogenic bacteria in hungarian finishing pigs. Acta Vet. Hung., 55(2): 219-227.

22. Burrough, E.R. (2017) Swine dysentery: Etiopathogenesis and diagnosis of a reemerging disease. Vet. Pathol., 54(1): 22-31.

23. Wilberts, B.L., Warneke, H.L., Bower, L.P., Kinyon, J.M. and Burrough, E.R. (2015) Comparison of culture, polymerase chain reaction, and fluorescent in situ hybridization for detection of Brachyspira hyodysenteriae and "Brachyspira hampsonii" in pig feces. J. Vet. Diagn. Invest., 27(1): 41-46.

24. Mushtaq, M., Zubair, S., Råsbäck, T., Bongcam-Rudloff, E. and Jansson, D.S. (2015) Brachyspira suanatina sp. nov., an enteropathogenic intestinal spirochaete isolated from pigs and mallards: Genomic and phenotypic characteristics. BMC Microbiol., 15(208): 1-13

25. La, T., Phillips, N.D., Coiacetto, F. and Hampson, D.J. (2019) An atypical weakly haemolytic strain of Brachyspira hyodysenteriae is avirulent and can be used to protect pigs from developing swine dysentery. Vet. Res., 50(1): 47.

26. Mahu, M., Boyen, F., Canessa, S., Zavala Marchan, J., Haesebrouck, F., Martel, A. and Pasmans, F. (2017) An avirulent Brachyspira hyodysenteriae strain elicits intestinal IgA and slows down the spread of swine dysentery. Vet. Res., 48(1): 59.

27. Mahu, M., de Pauw, N., Vande Maele, L., Verlinden, M., Boyen, F., Ducatelle, R., Haesebrouck, F., Martel, A. and 
Pasmans, F. (2016) Variation in hemolytic activity of Brachyspira hyodysenteriae strains from pigs. Vet. Res., 47(1): 66.

28. Hampson, D.J., La, T. and Phillips, N.D. (2015) Emergence of Brachyspira species and strains: Reinforcing the need for surveillance. Porcine. Health Manag. 1: 1-8.

29. Viott, A.M., Lage, A.P., Cruz Junior, E.C.C. and Guedes,
R.M.C. (2013) The prevalence of swine enteropathogens in Brazilian grower and finisher herds. Braz. J. Microbiol., 44(1): 145-151.

30. Dors, A., Czyżewska-Dors, E. and Woźniakowski, G. (2020) A survey on the occurrence of Brachyspira pilosicoli and Brachyspira hyodysenteriae in growing-finishing pigs. F1000Res., 8(1702): 1-11.

$* * * * * * * *$ 